\title{
Synthesis and characterization of impurities of an anticonvulsant drug, Pregabalin
}

\author{
Somaiah Sripathi, ${ }^{a}$ Narender Rao Somesetti, ${ }^{a}$ Raju Veeramalla, ${ }^{a}$ Nageswar Rao Challa, ${ }^{a}$ \\ Srinivasa Rao Peddi, ${ }^{a}$ and Venugopal Reddy Karnati*b \\ ${ }^{a}$ Department of Research and Development, Srini Pharmaceuticals Ltd., Plot No. 10, Type-C, \\ Road No. 8, Film Nagar, Jubilee Hills, Hyderabad-500033, Andhra Pradesh, India \\ ${ }^{b}$ Department of Chemistry, Osmania University, Tarnaka, Hyderabad- 500007, Andhra Pradesh, \\ India \\ E-mail: $\underline{\text { drkvrou@yahoo.com, kvgr1951@rediffmail.com }}$
}

\begin{abstract}
During the process development of Pregabalin 1, a known anticonvulsant drug, six potential impurities were identified in the final crude material ranging from 0.01 to $0.15 \%$ by LCMS. All six impurities were subsequently synthesized and characterized by IR, MS and NMR spectral data. Four of the six related substances are known as 4-isobutylpyrrolidin-2-one 6, 3isobutylglutaric acid 2, (R)-(-)-3-carbamoylmethyl-5-methylhexanoic acid 5 and (R)-(-)-3aminomethyl-5-methylhexanoic acid 8, whilst (S)-3-aminomethyl-5-methylhexanoic acid isobutyl ester 9 and $(S)$-3-aminomethyl-5-methylhexanoic acid isopropyl ester $\mathbf{1 0}$ are new compounds reported for the first time in our process. The present work describes the formation, synthesis and characterization of these impurities.
\end{abstract}

Keywords: Pregabalin, anticonvulsant, impurities, synthesis, characterization

\section{Introduction}

Pregabalin 1 ((S)-(+)-3-aminomethyl-5-methylhexanoic acid) is a novel and potent anticonvulsant agent for the treatment of epilepsy and pain. ${ }^{1}$ It has also been found to be more active than Gabapentin in preclinical models of epilepsy. ${ }^{2}$ It has more potent and robust activity in various models of epilepsy, neuropathic pain and anxiety. ${ }^{3}$

The presence of impurities in an active pharmaceutical ingredient (API) can have a significant impact on the quality and safety of the drug products. Therefore, it is necessary to study the impurity profile of the API to be used in the manufacturing of drug substance. International Conference on Harmonization ( $\mathrm{ICH}$ ) guidelines recommended identifying and characterizing all impurities that are present at a level of $0.10 \%$ or more. ${ }^{4,5}$ As Pregabalin 1 is an 
important drug substance and to obtain information on product profile, a comprehensive study was undertaken on the impurities generated during the process development (Scheme 1). ${ }^{6,7}$
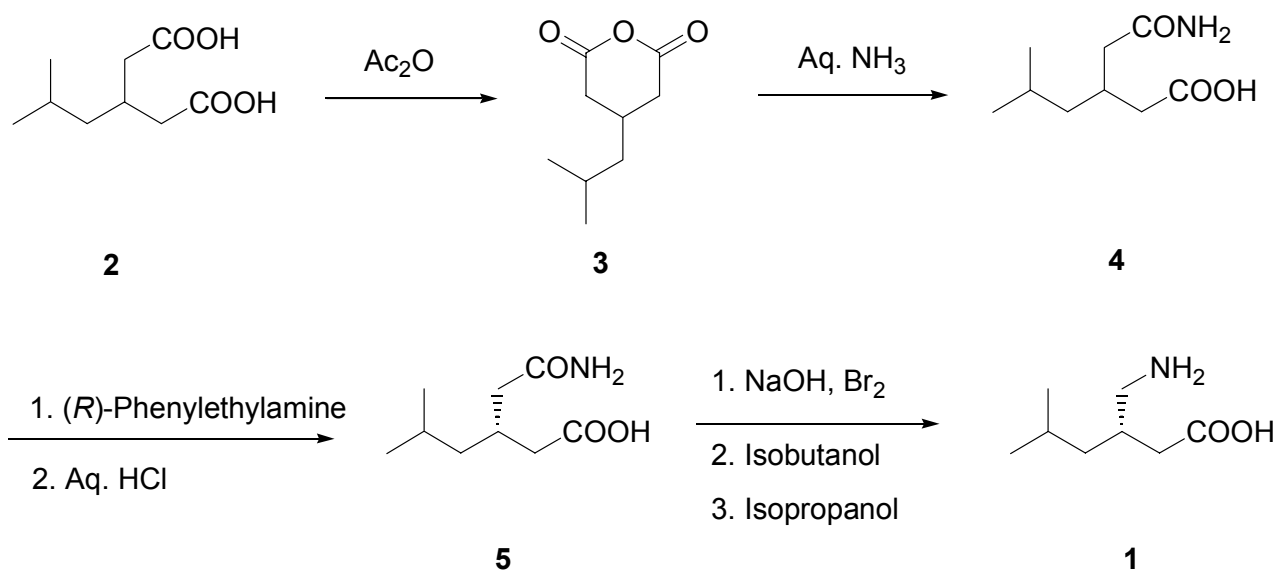

Scheme 1. Reported synthetic scheme for Pregabalin.

\section{Results and Discussion}

During the process development of Pregabalin 1, HPLC analysis of crude Pregabalin revealed six impurities ranging from $0.01-0.15 \%$. According to $\mathrm{ICH}$ (International Conference on Harmonization) guidelines the amount of acceptable level for known and unknown impurities in a final drug candidate must be less than $0.15 \%$ and $0.10 \%$ respectively. In order to meet the stringent regulatory requirements, the impurities needed to be identified and characterized. Hence, samples of Pregabalin 1 were initially analyzed by LCMS to provide parent ions at $\mathrm{m} / \mathrm{z}$ 142, 187, 188, 216, 202 for five related impurities and at $m / z 160$ for the enantiomer of Pregabalin 1, and thus provide a basis for initial identification. To confirm their proposed structures and complete their characterization, all six substances were individually synthesized and characterized by their respective IR, MS, and NMR spectral data. The structure of these related substances were assigned as 4-isobutylpyrrolidin-2-one 6, 3-isobutylglutaric acid 2, $(R)$ (-)-3-carbamoylmethyl-5-methylhexanoic acid 5, (S)-3-aminomethyl-5-methylhexanoic acid isobutyl ester 9, $(S)$-3-aminomethyl-5-methylhexanoic acid isopropyl ester 10 and (R)-(-)-3aminomethyl-5-methylhexanoic acid 8 respectively. 


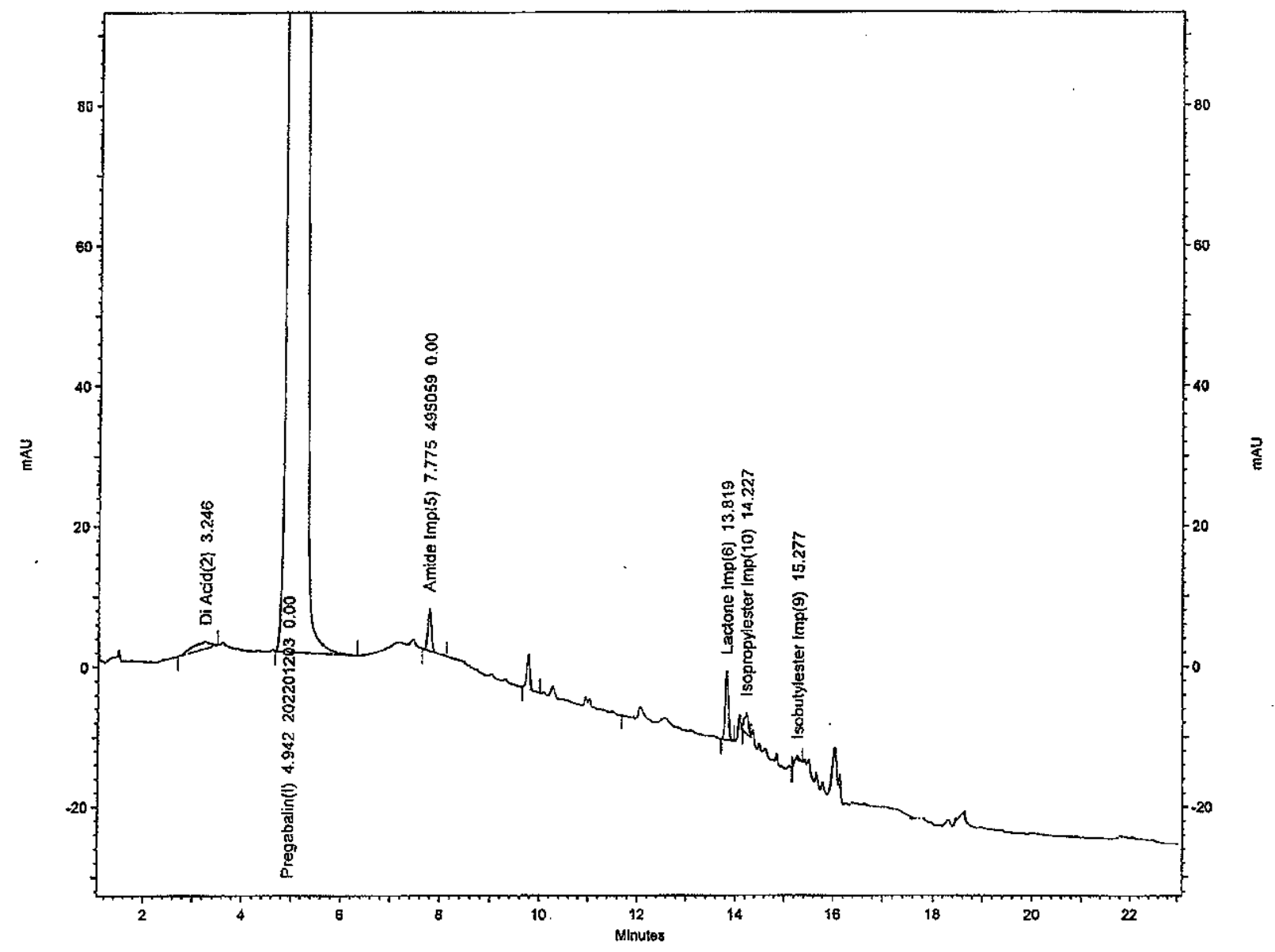

Figure 1. HPLC Chromatogram of pregabalin.
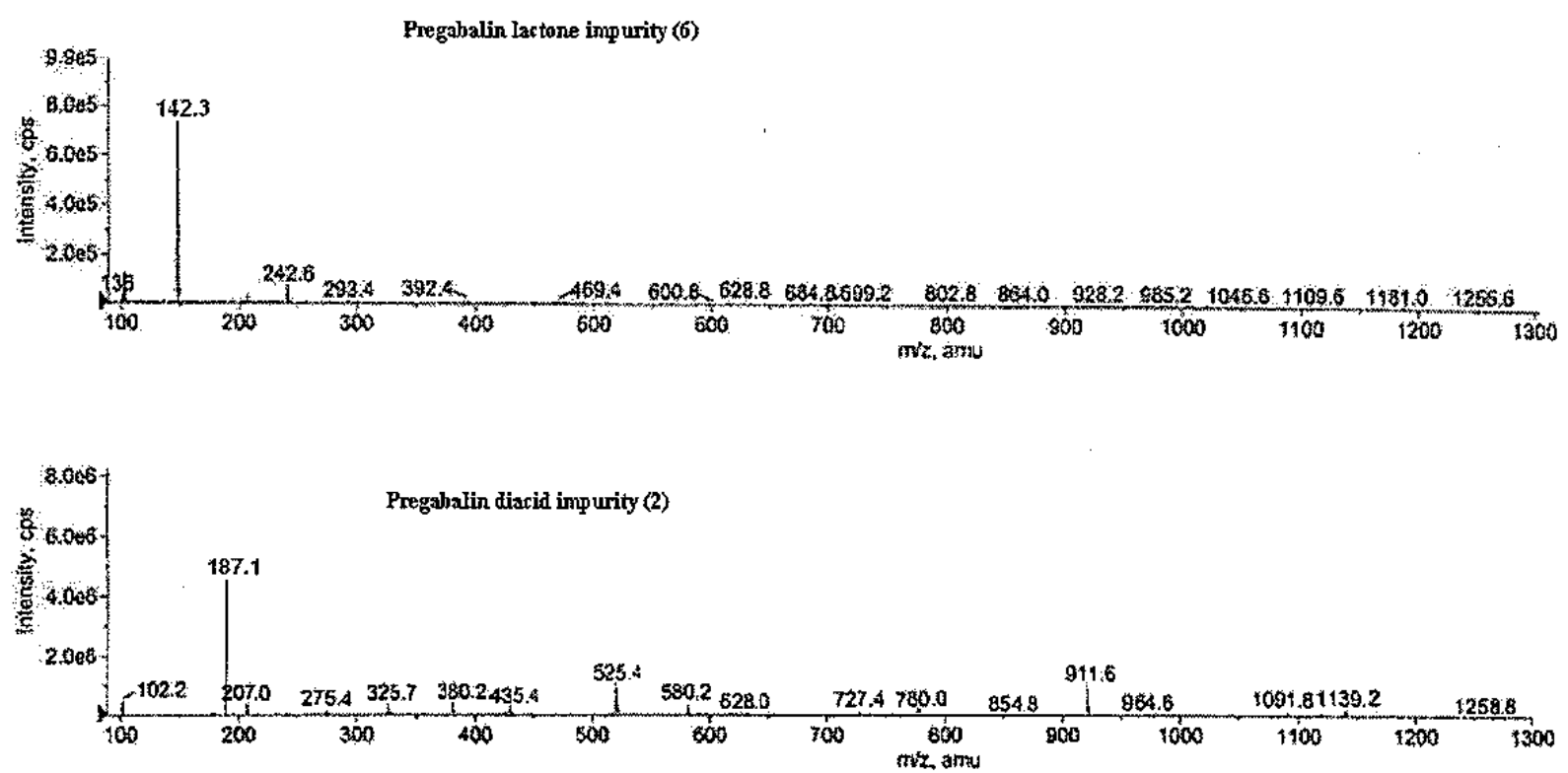

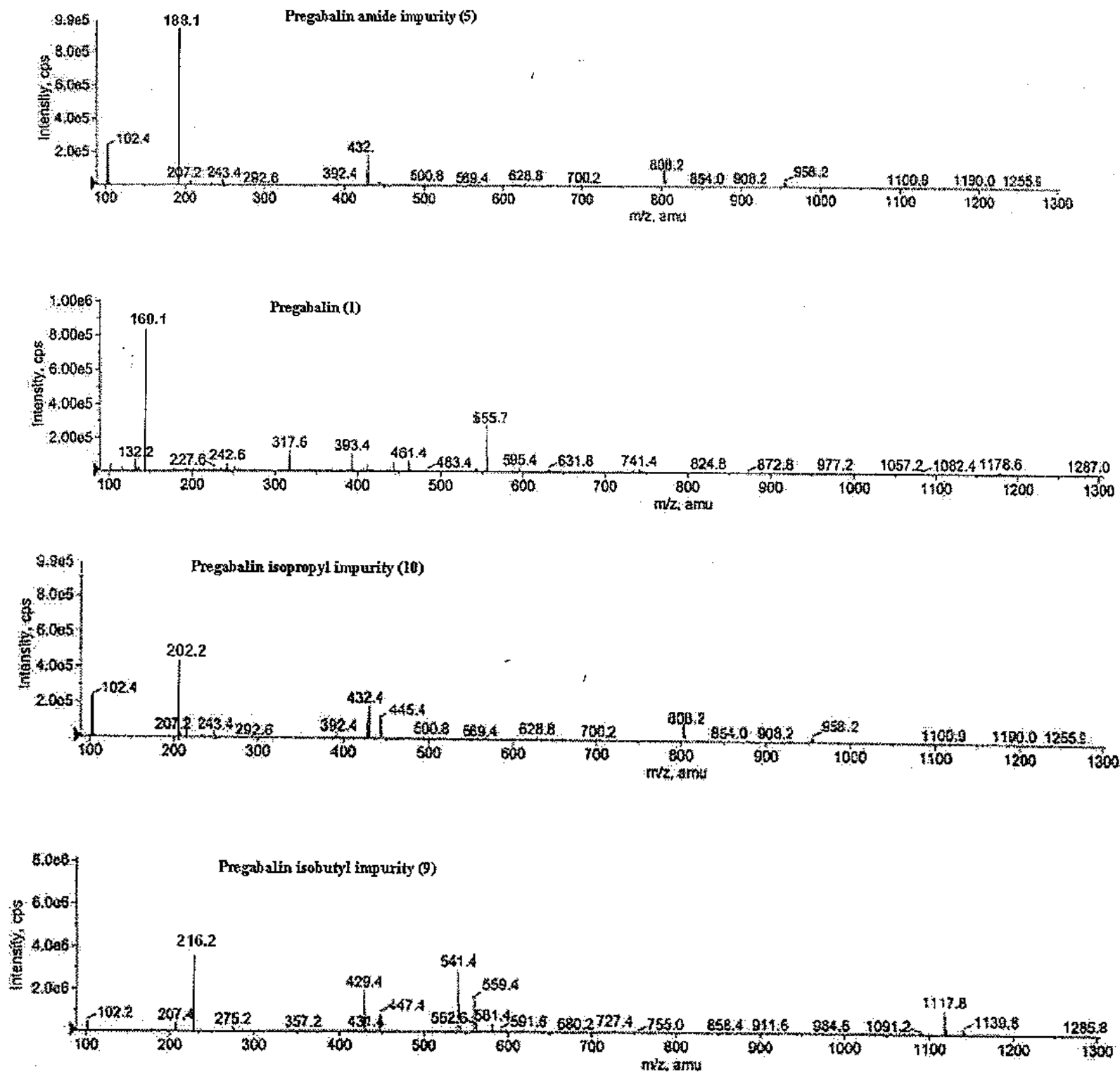

Figure 2. LC-MS Spectrum of pregabalin and its related substances.

\section{Formation of related compounds}

The substance 6 was formed during Hofmann reaction of (R)-(-)-3-carbamoylmethyl-5methylhexanoic acid 5 in the presence of bromine and sodium hydroxide. ${ }^{8 a}$ The related compound 6 was synthesized by the reaction of $(R)-(-)-3$-carbamoylmethyl-5-methylhexanoic acid 5 with excess of sodium hydroxide and bromine at elevated temperature (Scheme 2). The mass spectrum displayed a protonated molecular ion at $\mathrm{m} / z 142$ and the NMR spectrum showed a peak at $\delta 7.44 \mathrm{ppm}$ corresponding to cyclic amide $-\mathrm{NH}$ proton. Based on the spectral data the structure was confirmed as 4-isobutylpyrrolidin-2-one $\mathbf{6}$. 


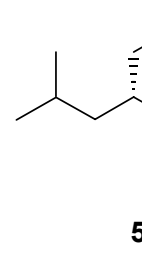

$\underset{\text { 2. Toluene }}{\stackrel{\mathrm{NaOH}, \mathrm{Br}_{2}}{\longrightarrow}}$

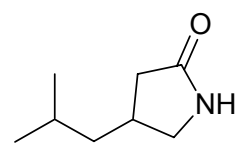

6

\section{Scheme 2}

Related substance 2, a potential impurity which is base hydrolyzed product during Hofmann reaction, ${ }^{8 \mathrm{~b}}$ was synthesized by the reaction of $(R)$-(-)-3-carbamoylmethyl-5-methylhexanoic acid 5 with excess of sodium hydroxide at elevated temperature (Scheme 3). The mass spectrum of compound 2, displayed a negative molecular ion at $\mathrm{m} / \mathrm{z} 187$ whilst in the IR spectrum a sharp band appeared at $1575 \mathrm{~cm}^{-1}$ corresponding to an aliphatic acid carbonyl and the spectral data is consistent with the structure of 3-isobutylglutaric acid 2.

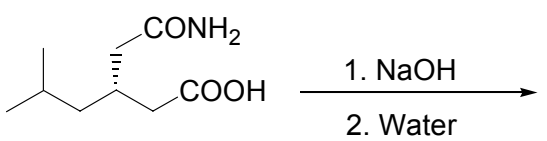

5

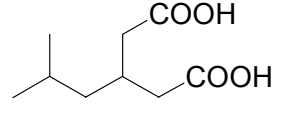

2

\section{Scheme 3}

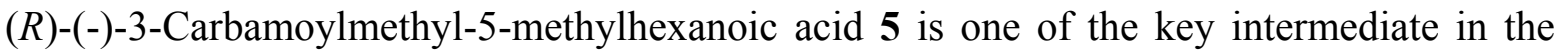
synthesis of Pregabalin 1. It was prepared by the resolution of racemic 3-carbamoylmethyl-5methylhexanoic acid 4 with $(R)$-1-phenylethylamine in the presence of chloroform and ethanol (Scheme 4). The mass spectrum of the substance 5, showed a protonated molecular ion at $\mathrm{m} / \mathrm{z}$ 188. The IR spectrum showed a sharp band at $1712 \mathrm{~cm}^{-1}$ corresponding to acid carbonyl and at $1644 \mathrm{~cm}^{-1}$ corresponding to amide carbonyl. The NMR spectrum displayed a peak at $\delta 6.76$ and $\delta$ $7.43 \mathrm{ppm}$ corresponding to amide $-\mathrm{NH}_{2}$ protons. Based on the spectral data, the structure was confirmed as (R)-(-)-3-carbamoylmethyl-5-methylhexanoic acid $\mathbf{5}$.

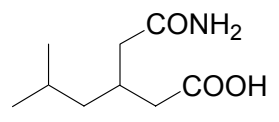

4

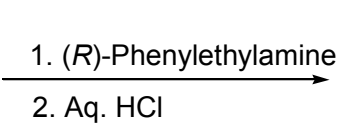

2. Aq. $\mathrm{HCl}$

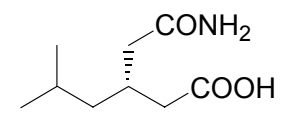

5

\section{Scheme 4}




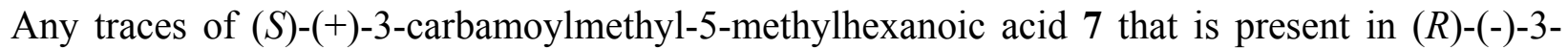
carbamoylmethyl-5-methylhexanoic acid 5 converts to enantiomer of Pregabalin i.e., $(R)-(-)-3-$ aminomethyl-5-methylhexanoic acid $\mathbf{8}$ during the Hofmann reaction with bromine and sodium hydroxide. Substance 8 was synthesized by the resolution of racemic amide 4 with $(S)$-1phenylethylamine in chloroform and ethanol followed by Hofmann reaction (Scheme 5). The mass spectrum of the substance 8 displayed a protonated molecular ion at $m / z 160$. The IR spectrum showed a sharp band at $1644 \mathrm{~cm}^{-1}$ corresponding to acid carbonyl and the specific optical rotation of $[\alpha]_{\mathrm{D}}{ }^{25}-10.7^{\circ}$ confirms the structure of $(R)$-(-)-3-aminomethyl-5methylhexanoic acid $\mathbf{8}$.

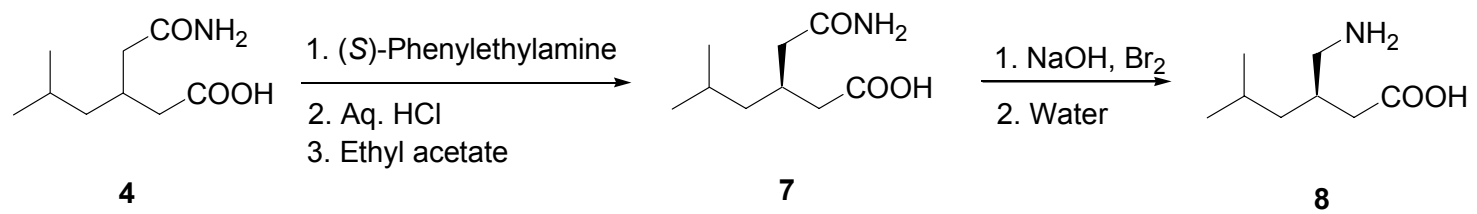

\section{Scheme 5}

Hofmann reaction of substance 5 with bromine and sodium hydroxide affords Pregabalin 1. However, as a side reaction isobutanol which is used as solvent for the extraction, reacts with $\mathbf{1}$ and leads to the formation of isobutyl ester of Pregabalin. This impurity was quantitatively synthesized in the form of hydrochloride salt by the reaction of Pregabalin $\mathbf{1}$ with thionyl chloride in the presence of isobutanol (Scheme 6). The mass spectrum of the substance 9 displayed a protonated molecular ion at $\mathrm{m} / z 216$ and a sharp band at $1727 \mathrm{~cm}^{-1}$ was observed in the IR spectrum which was attributed to ester $\mathrm{C}=\mathrm{O}$ stretching. The NMR spectrum exhibited 12 protons at $\delta 0.83-0.90 \mathrm{ppm}$ corresponding to four methyl groups and a doublet at $\delta 3.8 \mathrm{ppm}$ corresponding to two protons of methylene group adjacent to oxygen atom. Based on the spectral data, the structure of this impurity is assigned as (S)-3-aminomethyl-5-methylhexanoic acid isobutyl ester hydrochloride 9.

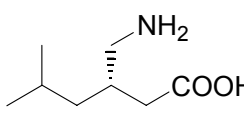

1

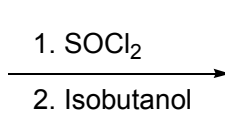

Isobutanol

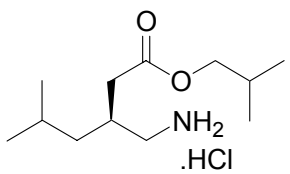

9

\section{Scheme 6}

During Hofmann reaction, isopropanol which is used as a solvent for isolation reacts with 1, as a side reaction and leads to the formation of isopropyl ester of Pregabalin. This impurity was synthesized in the form of hydrochloride salt by the esterification of Pregabalin 1 with thionyl chloride in the presence of isopropanol (Scheme 7). The mass spectrum of the substance 10 
displayed a protonated molecular ion at $\mathrm{m} / z 202$ and a sharp band at $1727 \mathrm{~cm}^{-1}$ was observed in the IR spectrum which was attributed to ester $\mathrm{C}=\mathrm{O}$ stretching. The NMR spectrum displayed a doublet at $\delta 1.2 \mathrm{ppm}$ corresponding to two methyl groups and a multiplet at $\delta 4.86-4.95 \mathrm{ppm}$ corresponding to $-\mathrm{CH}$ proton of isopropyl ester. Based on the spectral data the structure of this impurity is assigned as $(S)$-3-aminomethyl-5-methylhexanoic acid isopropyl ester hydrochloride 10.

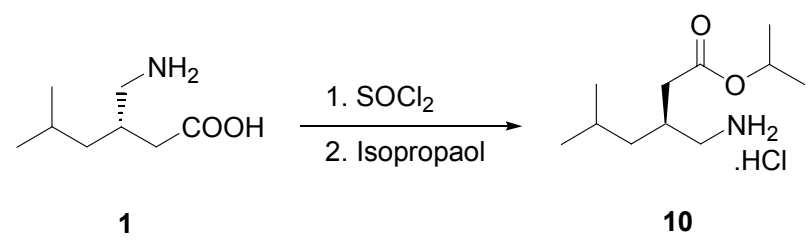

Scheme 7

\section{Conclusions}

In conclusion, we have identified, synthesized and characterized six potential process related impurities 2, 5, 6, 8, 9 and 10 of Pregabalin 1.

\section{Experimental Section}

General. The ${ }^{1} \mathrm{H}$ NMR was recorded in DMSO at $300 \mathrm{MHz}$ on a Bruker $300 \mathrm{MHz}$ FT NMR spectrometer. The chemical shifts were reported in $\delta \mathrm{ppm}$ relative to TMS. The FT-IR spectra were recorded in the solid state as $\mathrm{KBr}$ dispersion using a Perkin-Elmer 1650 FT-IR spectrophotometer. The mass spectrum (70 eV) was recorded on an Agilent-6310 LC-MS spectrometer. The solvents and reagents were used without any purification.

Preparation of 4-isobutylpyrrolidin-2-one (6). To a stirred mixture of water $(175 \mathrm{~mL})$ and sodium hydroxide $(29.2 \mathrm{~g}, 0.730 \mathrm{~mol})$ was added bromine $(25.5 \mathrm{~g}, 0.159 \mathrm{~mol})$ slowly for 45-60 $\min$ at -10 to $-5{ }^{\circ} \mathrm{C}$. Stirred the reaction mixture for $30 \mathrm{~min}$ and added $(R)-(-)-3-$ carbamoylmethyl-5-methylhexanoic acid 5 (25.0 g, 0.133 mol) in lot wise for 45-60 min at -10 to $-5{ }^{\circ} \mathrm{C}$. Slowly heated the reaction mixture to $85-90{ }^{\circ} \mathrm{C}$ over a period of $5 \mathrm{~h}$ and stirred for $8 \mathrm{~h}$ at the same temperature. After completion of reaction (TLC), extracted the compound with toluene $(2 \times 75 \mathrm{~mL})$ at $80-90{ }^{\circ} \mathrm{C}$ and washed the toluene layer with water $(50.0 \mathrm{~mL})$, removed the toluene completely under reduced pressure to get light yellow colored oily liquid 4-isobutylpyrrolidin-2one 6 (5.0 g, yield: $26.2 \%$, purity by HPLC 99\%). IR ( $\left.\mathrm{cm}^{-1}\right): 2924,1745 ;{ }^{1} \mathrm{H}$ NMR (DMSO- $d_{6}, \delta$ ppm): 0.84-0.88 (d, 6H, $\left.\mathrm{CH}_{3}, J 6.0 \mathrm{~Hz}\right), 1.24-1.29$ (t, 2H, $\left.\mathrm{CH}_{2}, J 6.0 \mathrm{~Hz}\right), 1.47-1.58(\mathrm{~m}, 1 \mathrm{H}, \mathrm{CH})$, 1.74-2.23 (dd, $2 \mathrm{H}, \mathrm{CH}_{2}, J 6.0 \mathrm{~Hz}$ ), 2.33-2.44 (m, 1H, CH), 2.78-2.83 (t, $\left.\mathrm{CH}_{2}, J 6.0 \mathrm{~Hz}\right), 7.44$ (s, 
$1 \mathrm{H}, \mathrm{NH}) ;{ }^{13} \mathrm{C}$ NMR (DMSO- $\left.d_{6}, \mathrm{ppm}\right): 176.95,47.89,43.91,37.35,32.86,26.15,22.92$; HRMS for $\mathrm{C}_{8} \mathrm{H}_{15} \mathrm{NO}[\mathrm{M}+\mathrm{H}]^{+}: \mathrm{m} / z$ Calcd: 142.1231; Found: 142.1227 .

3-Isobutylglutaric acid (2). To a mixture of water $(80 \mathrm{~mL})$ and sodium hydroxide $(21.4 \mathrm{~g}, 0.535$ mol) was added $(R)-(-)-3$-carbamoylmethyl-5-methylhexanoic acid $5(20.0 \mathrm{~g}, 0.106 \mathrm{~mol})$ and heated to $75-80{ }^{\circ} \mathrm{C}$, stirred for $5 \mathrm{~h}$ at the same temperature. After completion of reaction (TLC), cooled the reaction mixture to $25-30{ }^{\circ} \mathrm{C}$ and adjusted the $\mathrm{pH}$ to $\sim 7.0$ with aq. $\mathrm{HCl}$ solution, stirred for 30-45 $\mathrm{min}$ at $25-30^{\circ} \mathrm{C}$. Filtered the separated solid and washed with water $(10.0 \mathrm{~mL})$, dried at $50{ }^{\circ} \mathrm{C}$ under vacuum to afford 3-isobutylglutaric acid $2(17.0 \mathrm{~g}$, yield: $85 \%$, purity by HPLC 99.5\%). IR ( $\left.\mathrm{cm}^{-1}\right): 3436,2953,1575 ;{ }^{1} \mathrm{H} \mathrm{NMR}\left(\mathrm{D}_{2} \mathrm{O}, \delta \mathrm{ppm}\right): 0.70\left(\mathrm{~d}, 6 \mathrm{H}, \mathrm{CH}_{3}, J 6.0 \mathrm{~Hz}\right)$, 0.97 (s, 2H, $\left.\mathrm{CH}_{2}\right), 1.49$ (s, 1H, CH), $1.95\left(\mathrm{~s}, 4 \mathrm{H}, \mathrm{CH}_{2}\right), 2.05$ (s, $\left.1 \mathrm{H}, \mathrm{CH}\right) ;{ }^{13} \mathrm{C} \mathrm{NMR}\left(\mathrm{D}_{2} \mathrm{O}, \mathrm{ppm}\right)$ : 182.89, 43.66, 31.90, 24.60, 22.27; MS: m/z: $187\left(\mathrm{M}-\mathrm{H}^{+}\right)$; Analysis calcd. for $\mathrm{C}_{9} \mathrm{H}_{16} \mathrm{NO}_{4}: \mathrm{C}$, $57.43 ; \mathrm{H}, 8.57 \%$ Found: C, $57.41 ; \mathrm{H}, 8.55 \%$.

(R)-(-)-3-Carbamoylmethyl-5-methylhexanoic acid (5). A mixture of 3-carbamoyl-methyl-5methylhexanoic acid $4(40.0 \mathrm{~g}, 0.213 \mathrm{~mol})$, chloroform $(464.0 \mathrm{~mL})$, ethanol $(9.6 \mathrm{~mL})$ and $R-(+)-$ phenylethylamine $(18.9 \mathrm{~g}, 0.156 \mathrm{~mol})$ was heated to $55-60{ }^{\circ} \mathrm{C}$, stirred for $45 \mathrm{~min}$. The reaction mixture was cooled to $25-30{ }^{\circ} \mathrm{C}$ in $60 \mathrm{~min}$ and stirred for $1 \mathrm{~h}$ then cooled to $10-15{ }^{\circ} \mathrm{C}$ and stirred for $60 \mathrm{~min}$. Filtered the separated solid and washed with chloroform $(20.0 \mathrm{~mL})$, suck dried for 1 h. To the wet cake charged water $(200 \mathrm{~mL})$, stirred for $10-15 \mathrm{~min}$ and adjusted the $\mathrm{pH}$ to $1-2$ with aq. $\mathrm{HCl}$ at $0-5{ }^{\circ} \mathrm{C}$, stirred for $45 \mathrm{~min}$. Filtered the solid and washed with water $(20.0 \mathrm{~mL})$, dried at $50{ }^{\circ} \mathrm{C}$ under vacuum to afford $(R)-(-)-3$-carbamoylmethyl-5-methylhexanoic acid 5 (16.0 g yield: $40 \%$, purity by HPLC $99.4 \%$ ). IR $\left(\mathrm{cm}^{-1}\right): 3436,3333,3227,2959,1712,1644 ;{ }^{1} \mathrm{H}$ NMR (DMSO- $d_{6}, \delta$ ppm): 0.56-0.92 (d, 6H, $\mathrm{CH}_{3}, J 6.0 \mathrm{~Hz}$ ), 1.09 (t, 2H, $\left.\mathrm{CH}_{2}, J 6.0 \mathrm{~Hz}\right), 1.49-1.64(\mathrm{~m}$, $1 \mathrm{H}, \mathrm{CH}), 1.87-2.34$ (m, 5H, $\mathrm{CH}_{2} \& \mathrm{CH}$ ), 6.76-7.3 (s, 2H, Amide - $\left.\mathrm{NH}_{2}\right), 12.05$ (s, 1H, Acid-OH); ${ }^{13} \mathrm{C}$ NMR (DMSO- $\left.d_{6}, \mathrm{ppm}\right): 174.27,173.99,42.96,29.63,24.46,22.5$; MS: $m / z: 188\left(\mathrm{M}+\mathrm{H}^{+}\right)$; Analysis calcd. for $\mathrm{C}_{9} \mathrm{H}_{17} \mathrm{NO}_{3}$ : C, 57.73; H, 9.15; N, 7.48\% Found: C, 57.68; H, 9.15; N, 7.69\%. (R)-(-)-3-Aminomethyl-5-methylhexanoic acid (8). A mixture of 3-carbamoylmethyl-5methylhexanoic acid $4(40.0 \mathrm{~g}, 0.213 \mathrm{~mol})$, chloroform $(464.0 \mathrm{~mL})$, ethanol $(9.6 \mathrm{~mL})$ and $S-(-)-$ phenylethylamine $(18.9 \mathrm{~g}, 0.156 \mathrm{~mol})$ was heated to $55-60{ }^{\circ} \mathrm{C}$, stirred for $45 \mathrm{~min}$. The reaction mixture was cooled to $25-30{ }^{\circ} \mathrm{C}$ in $45-60$ min and stirred for $1 \mathrm{~h}$ then cooled to $10-15{ }^{\circ} \mathrm{C}$ and stirred for 45-60 min. Filtered the separated solid and washed with chloroform $(20.0 \mathrm{~mL})$, suck dried for $1 \mathrm{~h}$. To the wet cake charged water $(200 \mathrm{~mL})$, stirred for 10-15 min. and adjusted the $\mathrm{pH}$ to 1-2 with aq. $\mathrm{HCl}$ at $0-5{ }^{\circ} \mathrm{C}$, stirred for $45 \mathrm{~min}$, filtered the solid and washed with water $(20.0 \mathrm{~mL}$ ), suck dried for $2 \mathrm{~h}$ to afford $(S)-(+)$-3-carbamoylmethyl-5-methylhexanoic acid 7 $(16.0 \mathrm{~g})$. Charged the semi dried compound 7 into a mixture of water $(80.0 \mathrm{~mL})$ and sodium hydroxide $(18.8 \mathrm{~g}, 0.47 \mathrm{~mol})$, stirred for $5-10 \mathrm{~min}$. Cooled the reaction mixture to $0-5{ }^{\circ} \mathrm{C}$, added bromine (14.5 g, 0.09) for $1-2 \mathrm{~h}$ and stirred for $2 \mathrm{~h}$ at $20-25{ }^{\circ} \mathrm{C}$. Poured the mass into aq. $\mathrm{HCl}$ $(\sim 36.0 \mathrm{~mL})$ solution at below $20^{\circ} \mathrm{C}$. Extracted the compound with isobutanol $(80.0 \mathrm{~mL})$ and adjusted the $\mathrm{pH}$ to 7.0 with triethyl amine $(\sim 12 \mathrm{~mL})$ at $25-30{ }^{\circ} \mathrm{C}$ and stirred for $60 \mathrm{~min}$ at $0-5^{\circ} \mathrm{C}$. Filtered the isolated solid, washed with isobutanol $(8.0 \mathrm{~mL})$ and finally the wet compound was recrystalized from isopropanol and water (1:1) to yield $(R)-(-)-3$-aminomethyl-5-methylhexanoic 
acid 8 (7.0 g, yield: 20.6\%, purity by HPLC 99.6\%). IR $\left(\mathrm{cm}^{-1}\right): 2955,1644 ;{ }^{1} \mathrm{H}$ NMR $\left(\mathrm{D}_{2} \mathrm{O}, \delta\right.$ ppm): 0.83 (d, $\left.6 \mathrm{H}, \mathrm{CH}_{3}, J 6.0 \mathrm{~Hz}\right), 1.15$ (t, $2 \mathrm{H}, \mathrm{CH}_{2}, J 6.0 \mathrm{~Hz}$ ), 1.52-1.63 (m, 1H, CH), 2.05-2.29 (m, 3H, $\left.\mathrm{CH}_{2} \& \mathrm{CH}\right), 2.84-2.98\left(\mathrm{~m}, 2 \mathrm{H}, \mathrm{CH}_{2}\right) ;{ }^{13} \mathrm{C}$ NMR $\left(\mathrm{D}_{2} \mathrm{O}, \mathrm{ppm}\right): 181.14,46.61,43.67$, 40.73, 31.67, 24.37, 21.99; MS: $m / z: 160\left(\mathrm{M}+\mathrm{H}^{+}\right)$; SOR $[\alpha]_{\mathrm{D}}^{25}:-10.7^{\circ}(\mathrm{c}=1 \%$ water $)$; Analysis calcd. for $\mathrm{C}_{8} \mathrm{H}_{17} \mathrm{NO}_{2}$ : C, $60.35 ; \mathrm{H}, 10.76 ; \mathrm{N}, 8.80 \%$ Found: $\mathrm{C}, 60.15 ; \mathrm{H}, 10.80 ; \mathrm{N}, 8.72 \%$.

(S)-3-Aminomethyl-5-methylhexanoic acid isobutyl ester hydrochloride (9). To a mixture of Pregabalin $(1,10.0 \mathrm{~g}, 0.062 \mathrm{~mol})$ and isobutanol $(50.0 \mathrm{~mL})$ was added thionyl chloride $(14.9 \mathrm{~g}$, $0.125 \mathrm{~mol}$ ) at $10-15{ }^{\circ} \mathrm{C}$ and slowly heated to reflux, stirred for $3-4 \mathrm{~h}$ at the same temperature. After completion of reaction (TLC), distilled out solvent completely under reduced pressure and purified the crude compound in n-hexane to afford (S)-3-aminomethyl-5-methylhexanoic acid isobutyl ester hydrochloride 9 (9.6 g, yield: $61 \%$, purity by HPLC $99.3 \%)$. IR $\left(\mathrm{cm}^{-1}\right): 2957$, 1727; ${ }^{1} \mathrm{H}$ NMR (DMSO- $d_{6}, \delta$ ppm): 0.83-0.90 (d, $\left.6 \mathrm{H}, \mathrm{CH}_{3}, J 6.0 \mathrm{~Hz}\right), 1.03-1.29\left(\mathrm{~m}, 2 \mathrm{H}, \mathrm{CH}_{2}\right.$ ), 1.56-1.62 (m, 1H, CH), 1.82-2.18 (m, $\left.2 \mathrm{H}, \mathrm{CH}_{2}\right), 2.2-2.34(\mathrm{~m}, 1 \mathrm{H}, \mathrm{CH}), 2.54-2.61(\mathrm{~m}, 1 \mathrm{H}, \mathrm{CH})$, 2.75-2.77 (d, $\left.2 \mathrm{H}, \mathrm{CH}_{2}, J 6.0 \mathrm{~Hz}\right), 3.81-3.83\left(\mathrm{~d}, 2 \mathrm{H}, \mathrm{CH}_{2}, J 6.0 \mathrm{~Hz}\right), 8.1\left(\mathrm{~s}, 3 \mathrm{H}, \mathrm{NH}_{3}{ }^{+} \mathrm{Cl}^{-}\right) ;{ }^{13} \mathrm{C}$ NMR (DMSO- $\left.d_{6}, \mathrm{ppm}\right): 172.22,70.25,42.74,36.61,31.44,27.71,24.94,22.94,20.18,19.34$; MS: $m / z: 216\left(\mathrm{M}+\mathrm{H}^{+}\right)$; Analysis calcd. for $\mathrm{C}_{12} \mathrm{H}_{25} \mathrm{NO}_{2}: \mathrm{C}, 66.93 ; \mathrm{H}, 11.70 ; \mathrm{N}, 6.50 \%$ Found: $\mathrm{C}$, $66.81 ; \mathrm{H}, 11.42 ; \mathrm{N}, 6.40 \%$.

(S)-3-Aminomethyl-5-methylhexanoic acid isopropyl ester hydrochloride (10). To a mixture of Pregabalin $(1,10.0 \mathrm{~g}, 0.062 \mathrm{~mol})$ and isopropanol $(50.0 \mathrm{~mL})$ was added thionyl chloride (14.9 g, $0.125 \mathrm{~mol}$ ) at $10-15{ }^{\circ} \mathrm{C}$ and slowly heated to reflux, stirred for $3-4 \mathrm{~h}$ at the same temperature. After completion of reaction (TLC), distilled out solvent completely under reduced pressure and purified the crude compound in n-hexane to afford (S)-3-aminomethyl-5-methylhexanoic acid isopropyl ester hydrochloride (10, $9.4 \mathrm{~g}$, yield: $63.0 \%$, purity by HPLC $99.3 \%)$. IR $\left(\mathrm{cm}^{-1}\right): 2959$, 1727; ${ }^{1} \mathrm{H}$ NMR (DMSO- $\left.d_{6}, \delta \mathrm{ppm}\right): 0.83-0.87\left(\mathrm{~d}, 6 \mathrm{H}, \mathrm{CH}_{3}, J 6.0 \mathrm{~Hz}\right), 1.02-1.11(\mathrm{~m}, 1 \mathrm{H}, \mathrm{CH})$, 1.17-1.20 (d, $\left.6 \mathrm{H}, \mathrm{CH}_{3}, J 6.0 \mathrm{~Hz}\right), 1.23-1.64\left(\mathrm{~m}, 2 \mathrm{H}, \mathrm{CH}_{2}\right), 2.11-2.27\left(\mathrm{~m}, 2 \mathrm{H} \mathrm{CH}_{2}\right), 2.53-2.55(\mathrm{~m}$, $1 \mathrm{H}, \mathrm{CH}), 2.74-2.75\left(\mathrm{~m}, 2 \mathrm{H}, \mathrm{CH}_{2}\right), 4.86-4.95(\mathrm{~m}, 1 \mathrm{H}, \mathrm{CH}), 8.1\left(\mathrm{~s}, 3 \mathrm{H}, \mathrm{NH}_{3}{ }^{+} \mathrm{Cl}^{-}\right) ;{ }^{13} \mathrm{C} \mathrm{NMR}$ (DMSO- $d_{6}, \mathrm{ppm}$ ): 171.13, 67.17, 41.85, 38.6, 36.45, 31.04, 24.46, 22.35, 21.55. MS: $\mathrm{m} / z: 202$ $\left(\mathrm{M}+\mathrm{H}^{+}\right)$; Analysis calcd. for $\mathrm{C}_{11} \mathrm{H}_{23} \mathrm{NO}_{2}: \mathrm{C}, 65.63 ; \mathrm{H}, 11.52 ; \mathrm{N}, 6.96 \%$ Found: $\mathrm{C}, 65.52 ; \mathrm{H}$, $11.42 ; \mathrm{N}, 6.68 \%$.

\section{Acknowledgements}

We thank the management of R\&D, Srini Pharmaceuticals Ltd., for supporting this work. Cooperation from analytical group colleagues is highly appreciated. 


\section{References}

1. (a) Yuen, P.; Kanter, G. D.; Taylor, C. P.; Vartanian, M. G. Bioorg. Med. Chem. Lett. 1994, 4, 823-826. (b) Bryans, J. S.; Davies, N.; Gee, N. S.; Dissanayake, V. U. K.; Ratcliffe, G. S.; Horwell, D. C.; Kneen, C. O.; Morrel, A. I.; Oles, R. J.; O’Toole, J. C.; Perkins, G. M.; Singh, L.; Suman-Chauhan, N.; O’Neill, J. A. J. Med. Chem. 1998, 41, 1838-1845. (c) Butters, M.; Catterick, D.; Craig, A.; Curzons, A.; Dale, D.; Gillmore, A.; Green, S. P.; Marziano, I.; Sherlock, J.-P.; White, W. Chem. Rev. 2006, 106, 3002-3027.

2. (a) Belliotti, T. R.; Capiris, T.; Ekhato, V.; Kinsora, J. J.; Field, M. J.; Heffner, T. G.; Meltzer, L. T.; Schwarz, J. B.; Taylor, C. P.; Thorpe, A. J.; Vartanian, M. G.; Wise, L. D.; Zhi-Su, T.; Weber, M. L.; Wustrow, D. J. J. Med. Chem. 2005, 48, 2294-2307. (b) Taylor, C. P. In New Trends in Epilepsy Management; Chadwick, D., Ed.; Royal Society of Medicine Services Ltd: London, 1993; pp 13-40.

3. (a) Huckle, R. Curr. Opin. Investig. Drugs 2004, 5, 82. (b) Lauria-Horner, B. A.; Pohl, R. B. Expert Opin. Investig. Drugs 2003, 12, 663.

4. International Conference on Harmonization guidelines Q3A (R) Impurities in New Drug Substances February 2002 (this guideline provides guidance for registration application on the content and qualification of impurities in new drug substances produced by the chemical synthesis).

5. International Conference on Harmonization guidelines Q3B (R) Impurities in New Drug Substances February 2002 (Guidance for registration or marketing application on the content and qualification of impurities in new drug product.

6. Huckabee, B. K.; Sobieray, D. M. U.S. Patent 5,616,793, 1997.

7. Hedvati, L.; Dee-Noor, Z.; Singer, C.; Pilarski, G.; Raizi, Y.; Tomer, S. WO 2006/122255 A1.

8. (a) Hedvati, L.; Pilarski, G.; Raizi, Y.; Tomer, S.; Dee-Noor, Z.; Singer, C. US 2006/0281816 A1; (b) Hedvati, L.; Pilarski, G.; Raizi, Y.; Tomer, S.; Dee-Noor, Z.; Singer, C. US 2006/0276544 A1. 